\title{
The Fractured Self: Exploring Selfhood in the Neuronovel The Echo Maker and the Neuromemoir Brain on Fire
}

\section{Bonnie Cross}

\section{(2) OpenEdition Journals}

Electronic version

URL: https://journals.openedition.org/ejas/17560

DOI: 10.4000/ejas.17560

ISSN: 1991-9336

Publisher

European Association for American Studies

\section{Electronic reference}

Bonnie Cross, "The Fractured Self: Exploring Selfhood in the Neuronovel The Echo Maker and the Neuromemoir Brain on Fire", European journal of American studies [Online], 16-4 | 2021, Online since 01 December 2021, connection on 07 July 2022. URL: http://journals.openedition.org/ejas/17560 ; DOI: https://doi.org/10.4000/ejas. 17560

This text was automatically generated on 7 July 2022.

\section{(C) $(1)(8$}

Creative Commons - Attribution-NonCommercial 4.0 International - CC BY-NC 4.0 https://creativecommons.org/licenses/by-nc/4.0/ 


\section{The Fractured Self: Exploring Selfhood in the Neuronovel The Echo Maker and the Neuromemoir Brain on Fire}

\section{Bonnie Cross}

\section{Introduction}

1 In 2008, Gary Johnson described "neuronarrative" as "a work of fiction that has cognitive science as a, or the, main theme" (170). As neuronarrative can refer to both fiction and memoir, it will be used in this paper to refer to both neuronovels and neuromemoirs. Neuronovels can be widely viewed as an attempt to understand how the neurotypical or non-neurotypical brain sees the world and tries to make sense of it. Jason Tougaw argues in The Elusive Brain: Literary Experiments in the Age of Neuroscience that, "Brain memoirs and so-called neuronovels conceive the physical brain as central to the stories they tell, the conflicts they plot, and the characters they portray; both genres engage brain research, translating neurobiological theories into literary experiments" (3). Neuronovels and brain memoirs utilize narrative to play with the interconnections between the self, the body, and the mind while interacting with the outside world (Tougaw 3 ).

2 Some neuronarratives struggle to smoothly incorporate scientific terminology alongside the narrative, which can create a disjointed structure. For Johnson, novelists writing in this genre "struggle to approach consciousness as content" (172). The authors feel they must pause the narrative and educate the audience about neurological terms to explain what is happening, which Johnson describes as the "novelist's perceived need to inform his or her audience about the current state of neuroscience" (174). If the audience isn't familiar with the neurological concepts that the narrative is working with, a large element of the story will be lost; however, the 
novel will lose the flow of the narrative if it becomes a textbook. Science fiction novels, such as The Martian (2011) by Andy Weir, face similar issues of balancing the science with the narrative. In Weir's novel, the protagonist Mark Watney must utilize his scientific background to survive on Mars, making the science a key component of the text rather than a distractor. Many neuronarratives follow a similar balancing act by incorporating neuroscience to better explain their experiences.

While Johnson points out that many in the Humanities and Sciences are wary about combining the disciplines, he is optimistic about the future of neuronarratives. He claims that this process of exploring the scientific aspects of "human consciousness... has the potential to refresh and redeem the field of literature" (184). Neuronarratives have value in potentially filling gaps that cannot be described through a single discipline. In The Elusive Brain, Tougaw argues that neuronarratives are attempts to fill the explanatory gap. Philosopher Joseph Levine described this term in his article "Materialism and Qualia: The Explanatory Gap" published in 1983. The explanatory gap refers to the fact that, regardless of our understanding of mechanisms behind neurological processes such as experiencing pain, we have no clear explanation for how our consciousness is formed or where selfhood comes from. Neuronovelists aim to create a way of understanding how their characters perceive themselves, the world around them, and their social relationships. While not all neuronarratives follow the same structure, the focus on multiple aspects of perception can result in multilinearity seen in Saturday by Ian McEwan and the additions of other voices or perspectives such as in Lowboy by John Wray. These shifts in time or additional voices are helpful to gain an understanding of the characters within a neuronarrative and show the complexity of our thought process.

4 This paper will focus on two works: the neuronovel The Echo Maker (2006) by Richard Powers, which is a fictional account of Mark Schluter who suffers from Capgras Syndrome, a rare neurological condition that results in the patient's belief that their loved ones have been replaced with exact copies; and the neuromemoir Brain on Fire: My Month of Madness (2012) by Susannah Cahalan, which describes Cahalan's experiences as she is diagnosed with anti-NMDA receptor encephalitis, a rare auto-immune disease. ${ }^{1}$ Both works have protagonists that suffer from a serious brain illness and must rely on their own perceptions, those of family and friends, and neuroscientific research in order to heal and create a more cohesive sense of self again.

5 While these works may be easily differentiated as a work of fiction and a memoir, both provide a unique perspective to how selfhood is understood and created after brains are damaged. Both Mark and Cahalan feel their identities have been fractured due to their conditions and they struggle to identify what is real. I argue that The Echo Maker and Brain on Fire complicate the perception of selfhood as the main character in each text can no longer trust their own perceptions and must instead weave together their fragmented personal experience, background from their social groups, and scientific explanations of their conditions to regain a sense of self. The narratives of The Echo Maker and Brain on Fire combine these different perspectives in an effort to regain a sense of selfhood that brain damage has fractured.

6 As neuronarratives widely vary by their focus on neuroscience and narrative, the goal of this paper is not to make an overreaching argument, but rather to showcase how reading The Echo Maker and Brain on Fire as a search for selfhood smooths out these disparate sections between their fragmented personal experiences and the 
neuroscientific explanations. This combination of narrative and scientific terminology allows critical engagement with both the text and the reader's perceived understanding of the brain and of the self. Despite our utter reliance on consciousness to perceive the world, it is an incredibly fragile and ever-changing thing that still battles against definition.

\section{Seeking Selfhood}

7 Neuronovels, as Francisco Ortega and Fernando Vidal claim, do not deconstruct humans to simply cerebrally controlled creatures, but ultimately provide an intimate view of selfhood through their focus on memory (332). The Echo Maker is innately focused on memory as Mark is unable to trust his memories due to his illness. He is forced into deeper delusions as he struggles to understand how this stranger, who looks so much like his sister, knows his history and previous relationship with his real sister. As he cannot connect to this lookalike, these delusions lead him to believe that he is inside of a conspiracy and that his sister has been replaced. Memories are a critical component for building relationships with others and creating an image of yourself. As Mark questions his copied sister, he must also question his relationships with everyone in his social circle and even wonders if he himself has been altered. The Echo Maker's structure provides multiple characters' perspectives per chapter. The advantage of this multiple perspective structure is the ability to understand how terrifying the prospect of loved ones being replaced would feel like to Mark while also allowing Karin's perspective to focus on the heartbreak and fear of being rejected by her brother.

8 Brain on Fire is a neuromemoir that also uses a multiple perspective within its narrative structure. Through the combination of case study notes with personal narrative, interviews, and video transcripts, Cahalan creates a patient-oriented account of her illness. Tougaw argues that neuromemoirs allow their authors to regain "agency," provide information to others who are suffering, "renew and invigorate philosophical debates about mind and body, qualia, memory, and relationships between self and narrative," and create new narrative structures (75). In Brain on Fire, Cahalan's goal is to understand what has happened to her and to articulate how she is learning to live after recovering from her illness. Tougaw argues that many memoirs take "selfhood for granted," but "brain memoirs investigate how mind, brain, body, and culture interact to create or perform selfhood, and that investigation has social, scientific, and philosophical implications" (76). Throughout the neuromemoir, Cahalan compares her previous understanding of herself and how others view her to try to mark progress or loss as she moves forward with her treatment. She argues that she never truly regains the "old Susannah" and instead ends her neuromemoir with the "new Susannah" (Cahalan 239). Ultimately, this neuromemoir is Cahalan's search for herself.

While Brain on Fire uses a similar narrative structure to The Echo Maker as Cahalan struggles to overcome her illness, one key difference is that while outside opinions are included in Cahalan's neuromemoir, they are still told through Cahalan's perspective. The multiple perspectives come from Cahalan herself as she covers the events both as her past self during her illness and as a narrator who has already recovered. As Cahalan's thought process was clearly affected by her illness, she must piece together the experience after her recovery. In many sections of the story, Cahalan argues that 
she is hidden somewhere within herself, present and absent within the same body. Cahalan separates herself as the narrator and future Cahalan who has already recovered, and the ill Cahalan who is still experiencing the symptoms of her undiagnosed condition. To fill in the gaps that she has no recollection of herself, she pulls information from multiple family members and friends as well as medical documentation to recreate her memory of the events.

Lindsay Starck uses the metaphor of a stereoscopic, a tool that combines two slightly different versions of the same picture to create a new, more detailed image, to explain memory as "the presentation of the two selves, the two images, the two realities side by side that creates depth and meaning by establishing connections between them" (Starck 338). Instead of just two perspectives coming together to create a full memory, in their respective texts, both Mark and Cahalan combine their memories with those of their friends and family members and a neuroscientific explanation for the events to create a threefold description of the same moment. However, instead of clarifying muddled moments in Mark's memory, this gathering of information sometimes creates contradictions when the information from the social group and the neuroscience does not match with his experience. Mark feels no emotional connection to Karin, so she must be an imposter. As the evidence that she is actually his sister piles up, Mark is forced to create more complex conspiracy theories and attempts to have Dr. Gerald Weber, a famous neuroscientist known for unique case studies, validate his delusions to provide an explanation for the lack of connection to his sister. Even though he initially trusted some of his friends, they too became part of the conspiracy, and did play a role in his accident, so even restoring his memory and emotional connection leads to changes in their relationships.

In Brain on Fire, the purpose of the text is to restore Cahalan's agency by transforming her illness into a more cohesive experience. This process forces Cahalan to see herself heavily influenced through her illness or medication, and she struggles to associate this version of herself with her mental self-image of her healthy self. Through the structure of her neuromemoir, Cahalan regains her agency through the process of putting together the pieces of information that she has alongside those provided by her loved ones and doctors at the time of her illness. In both texts, the goal is to regain a sense of wholeness, but this process can only be completed through the act of breaking themselves into sections: their past healthy self, their ill self, and their recovering self. To continue with Starck's metaphor, it is only through the help of their social groups and medical experts that Mark and Cahalan are able to piece together their identities, creating the full image of themselves after recovering from their illness.

\section{Personal Perception of the Self}

Self-perception is key to consciousness: who am I, what am I experiencing, and how do I feel about it are all crucial questions to the foundation of selfhood. Mark's initial descriptions of his state of awareness in The Echo Maker are muddled as he is coming out of his coma. He struggles to speak and mainly repeats words that are spoken to him, a condition called echolalia. Though his sister walks with him, and his friends and girlfriend visit, Mark does not have a full understanding of what has happened, and he needs to be reminded of the accident several times a day. He states, "but once they work him, they let him lie... this he loves: when they give him his body back, and no 
need. Loves just lying still in the world buzz, all channels at once pouring through his skin" (Powers 49). Despite his ability to walk and speak, Mark does not feel in control of his own body and describes his interaction with others as having his body borrowed. His lack of connection to himself is seen in his response to Karin saying goodbye in the hospital, "Am I asleep? Am I gone? Wake me up-this is someone else's dream" (Powers 59). Here Mark not only questions his physical control over his body, but his control over his mind as well.

This shift in his thought process marks an important break as Mark can accept a lack of control over his body, but the idea that his perception of the world is wrong is not something that he can accept. The world is not only dream-like to him, but as he feels that he has no agency, the dream cannot be his, so he lashes out and demands to know who sent this false Karin. Despite being in the hospital himself, he does not equate the changes in his perception with an error on his part, but rather an elaborate plot that is being carried out around him. When Karin tries to reassure him that she is his sister, he responds, "You think you're my sister?.... If you think you're my sister, there's something wrong with your head" (59). Mark cannot accept that there is something wrong with his brain, therefore it must be this stranger who looks like his sister who is responsible. He makes regular comparisons to his version of Karin and the one standing in front of him, "My sister would have gotten me out of this place by now. My sister always got me out of all my jams. I'm in the biggest jam of my life. You've failed to get me out. Therefore, you can't be my sister" (Powers 89). While Karin acknowledged that her brother's argument "made a kind of demented sense," she is horrified by his repeated denials of their relationship (Powers 89). As his brain continues to rationalize Mark's disconnect to his sister's presence, he begins to question everyone around him as well.

Even when Mark returns home and sees his own dog, he struggles to identify what is real and what is a fake. Desperate to find proof, he grasps small changes Karin had made to his home as evidence that this place is a copy. Despite the clear affection from his dog, Mark argues that even he must have been replaced with an exact copy, screaming "You think I'm nuts! You think I'm blind. It's going to take a lot more than this to fool me" (Powers 86). He starts to call Karin, Kopy Karin, Karin Two, or Karbon Karin and his girlfriend Bonnie becomes suspect as well due to her association with Karin. As he becomes increasingly isolated, Mark later tells Dr. Weber, "It's like some horror flick, sometimes. I can't figure out what's going on. His eyes filled with animal alarm, ready to ask even this stranger for help" (Powers 115). Unable to trust his friends and family members, Mark's focus for the remainder of the text is not to get his treatment, but to prove to himself that his accident was part of a larger conspiracy to better explain his perceptions.

In Brain on Fire, Cahalan also struggles with her perception of reality as her illness progresses. Cahalan points out that she is an unreliable narrator as her memory is limited and this statement adds to the credibility of her story as she freely admits to gaps in her memory and moments that were not recorded. She states that her narrative, "is a journalist's inquiry into that deepest part of the self-personality, memory, identity-in an attempt to pick up and understand the pieces left behind" (Cahalan xi). Her goal is to blend the information that she has gathered and interpret it to re-create the events. The benefit of this process is to see the same events from multiple perspectives. Cahalan argues that, despite her research, her consciousness was 
greatly affected by the illness and her perception is unreliable, accounting for the need of multiple perspectives.

The very first scene depicted in Brain on Fire is actually a hallucination. Cahalan describes waking up, strapped to a bed, with "the purple lady" staring at her and a bracelet with the words "FLIGHT RISK" (xiv). She has no idea that this is actually a lie, in the moment and in her memory, this event actually occurred. This presents the reader with a major concern: what can we consider real in a memoir where the narrator's brain is unreliable? Is this event real because it is a true memory of a hallucination, or should it be disregarded as the purple lady does not exist? To follow this kind of narrative, Tougaw states that readers must "adapt to simulations of neurodivergent ways of being" and view these differences as a display of the narrator's cognitive perspective (135). Cahalan struggles to discern which of her experiences were true and which happened inside of her head. Throughout the story, she pulls from others to reconstruct sections that she cannot recall or trust to add validity to the events. However, as these are her experiences, she still will interrupt the narrative with her perceptions to place them into context with her now complete understanding of what was actually happening in her brain. While the story follows a chronological order, interjections from Cahalan form two versions: Cahalan in the past and Cahalan in the future. Both versions of Cahalan are needed to both explain the events and their context in the past, and combine this information with what she has learned in the present.

The introductory chapters of the story focus on the slow progression of symptoms from mild anxiety about bed bugs to loss of sense of time and paranoia. Cahalan describes physical symptoms which later become important in the diagnosis process, but it is the focus on her perception of reality that is the most disconcerting. A simple thing such as a painting becomes horrific, as she describes a painting of a clown whose face becomes distorted and lost in the color (Cahalan 16). Later she describes another of these out-ofbody experiences, sitting in her office and watching the walls and ceiling move (Cahalan 28). Both of these descriptions were from simply sitting in a chair, yet the scene becomes nightmarish through her illness. These specific moments of first-person perspective allow the reader to understand the perception of what Cahalan's environment was like to her in those moments.

While these scenes are disturbing by themselves, her awareness that something is clearly wrong makes the process more terrifying as she states to her colleague: "Something is really wrong. I'm seeing bright colors, crying uncontrollably. I can't control myself.... Do you think I'm having a nervous breakdown? Do you think I'm going nuts?" (Cahalan 33). Instead of a list of symptoms in a scientific text, the readers watch her slow breakdown as the realization that her illness is serious becomes clear. The structure of this neuromemoir is unique in that the readers will get the scientific explanation for what is occurring, while still understanding how terrifying this experience was for the author. The benefit of this multilinear structure is that the reader can have the in-moment description as well as the after-the-fact speaker concurrently. Cahalan separates her sense of self into multiple selves, however, they are all a part of her and it is through the process of writing this book that she tries to unite them to regain a sense of self. 


\section{Social Perspective and Self}

19 As brain injuries and illnesses can compromise perceptions of reality or result in loss of consciousness, other perspectives are critical to understand what has changed about the characters and to fill in blanks when the patient is unable to answer. Due to the nature of Mark's illness, he cannot trust the true nature and identities of his loved ones, so his social relationships are a critical component for the diagnostic process and for his eventual recovery. Karin is a key part of Mark's social circle, not only for her connection to Mark throughout his life, but through her research of his illness. When Mark's delusions began, she pushed for answers to understand his condition. Dr. Hayes, Mark's original doctor, tells Karin that Mark "knows he has a sister. He remembers everything about her. He knows you look like her and act like her and dress like her. He just doesn't think you are her" (60). Hayes emphasizes how difficult it is to measure emotional response which is an important point. While there are tests to view neurochemicals, skin tension, and eye movement or dilation, measuring love or intensity of feeling is dependent on the person's verbal explanation. Hayes claims that while Mark can remember everything about Karin, "he just doesn't... feel you sufficiently to believe you" which Karin equates to emotional blindness (61). While Hayes suggests time to heal, Karin does not accept that and reaches out to Weber to consult on Mark's case. Despite her debates about leaving Mark as he does not believe she is really his sister anyway, she remains beside him, trying to convince him that she is real.

20 Mark repeatedly tests Karin to prove that she is fake, but her correct answers only further his delusions that she is a copy. They even travel to the remains of their childhood home and when Karin remembers the layout and details about the house, Mark still cannot accept that she is his real sister, but instead continues with his delusion arguing, "it's distinctly possible she's reading his brain waves. Wireless scans, some kind of new digital thing" (Powers 371). Rather than take his detailed knowledge of his life growing up, including memories of his mother that he did not have, he trusts strangers such as Weber (who he refers to as Shrinky) and Barbara (the woman later revealed to be the cause of his accident as he swerved to avoid hitting her on the road). Even his relationship with his friends becomes more complicated after his accident.

21 As Mark refuses to believe his real connection to Karin, her struggles increase when Mark still connects to his friends, despite not accepting her as family. Mark's friends Rupp and Cain provide a useful comparison to Mark's previous personality and experiences as they continue to play games and return to their routine before Mark's accident. Rupp even promotes Mark's delusion when he gets annoyed at Karin for interrupting their video game claiming: "Our man here is right. Arab terrorists kidnaped Karin Schluter and replaced her with a foreign agent" (Powers 154). While Cain is concerned about Rupp's comment, Mark responds by laughing, upsetting Karin and making her leave the room. Karin believes that both Rupp and Cain had something to do with his accident, which later turns out to be true, but both friends lie about it until Mark recognizes the walkie talkie from the night of the accident. After discovering that his friends were speaking to him during the accident, but never told him, he refuses to interact with them again, leaving him even more isolated. However, Mark does slowly reconnect with others by the end of the novel, such as his childhood 
friend Daniel. These connections represent his experiences with his illness, while Mark regains his memory, the connections to his friends and family are distinctly changed.

Cahalan's neuromemoir also relies on social connections, as her perceptions were often distorted by her illness. The first of the pivotal moments in her illness are not even told through her perspective because she was experiencing a seizure and has no memory of the event itself. Instead, this first major event was described by her boyfriend Stephen (Cahalan 40). The writer Cahalan interrupts the narrative again reminding the reader that she is organizing the content of the story. She places this scene in time by stating this is her "first serious blackout" and that she "would never again be the same person" (Cahalan 41). She describes this as "purgatory between the real world and the cloudy, fictitious realm made up of hallucinations and paranoia" (Cahalan 41). As she is unable to trust her own perceptions of this time, she "would increasingly be forced to rely on outside sources to piece together this lost time" (Cahalan 41). This marks the transition between her personal experiences and more emphasis on the accounts of others to fill in the gaps.

Even during this "lost time," there are moments when Cahalan has a fragment of memory or is able to fill in information after being prompted by her friends or family. She also uses her friends and family to help note the difference in her behavior and verify what was "normal" or out of character. A phone call between her mother and younger brother reflects on Cahalan's insistence that she is manic-depressive, both family members are pulling on previous experiences to consider her argument. Cahalan notes, "it was still difficult for [her mother] to reconcile the old image that she had of her daughter as trustworthy, hardworking, and independent with the new, unpredictable, and dangerous one" (Cahalan 65). This section marks the change in sources as the remaining text relies heavily on other sources to fill in the blanks of her memory. In Reading Autobiography, Sidonie Smith and Julia Watson claim that when narrators feel lost in conflicting or confusing memories, they may pull from different techniques to try to evoke their memories through artifacts such as journals or photographs or by placing themselves within their social groups by relying on the accounts of others to prompt their own memory (Smith and Watson 23). Cahalan uses a variety of materials including phone calls, notebooks, and interviews to provide details for this lost time in her memory.

In traditional case studies, the period between the appearance of symptoms and the diagnosis may be limited to a single paragraph, but it is important to remember the period of uncertainty and the impact of this time on family members. Many people are involved in her recovery: her boyfriend visits her in the hospital and cares for her at home, her father comes to each doctor's visit with a notepad filled with notes, her divorced parents regularly meet to discuss specialists and update her medications, and her colleagues visit her in her hospital room. This expansion of materials used with the neuronarrative is critical as it clarifies that a single person is rarely truly alone and that a disability, disorder, or illness has a ripple effect into their social circles. Cahalan had several diagnoses and treatments before her final diagnosis, and she was not the only one impacted. She also required care from her friends and family to recover from her illness. 


\section{Scientific Perspective and Self}

Both texts rely on elements of neuroscience to explain the symptoms and experiences of brain injury and illness. The neuroscience within the fiction The Echo Maker has some grounding in real scientific studies. In a medical article published in 1997, W. Hirstein and V.S. Ramachandran noted that Capgras Syndrome patients have damage to their fusiform face area (the area responsible for recognizing human faces) and the connection to the limbic system (where we experience many of our emotions) (437). While the condition is very rare, the characteristics of Capgras Syndrome do match Mark's symptoms and delusions. For example, one of Mark's medications, Olanzapine, is a treatment for Capgras Syndrome (Torales et al.). There is also a real documented case of a patient that presented with Capgras, Fregoli and Cotard's Syndromes at once in a 2008 study, which supports Karin's initial diagnosis of her brother's condition (Yalin, Varol, and Gunevir). However, some authors such as Christian Knirsch have pointed out that there are many contradicting accounts of Capgras Syndrome and Power's interpretation is problematic. Several sections oversimplify the science behind Mark's treatment or gloss over important elements such as his treatment process.

Many of the oversimplification issues with the neuroscience in The Echo Maker involve the character Dr. Weber. Weber is introduced as a cognitive neurologist who is a prominent popularizer of science and has written several books about people with interesting neurological conditions, but many of his critics argue that his motivation is to sell stories and sensualize these conditions rather than help the patients. When he initially reads Karin's email asking for his help, Weber was going to decline to consult on Mark's case. However, he remains intrigued by the idea of a Capgras Syndrome patient, despite his desire to move on to a different book project. Weber's initial motives are decidedly less focused on Mark's recovery and more on the condition itself, with an even more ambitious goal of using Mark's case to gain an understanding of how consciousness is created.

Not only are Weber's motivations conflicted, but when Weber meets Mark and proceeds to test him, his tests are also problematic. While he records Mark's reactions to pictures of family and friends, he does not get a baseline reading, making most of the data useless. Weber himself notes this about halfway through the test, but does not make any adjustments. He also has Karin leave the room and call Mark on the phone, a technique that is based on real science as hearing the voice of a loved one uses a different area of the brain, one that may still have intact connections to the limbic system (Hirstein and Ramachandran 438). By calling on the telephone, the connection to the limbic system is not through facial recognition, but through voice recognition. In The Echo Maker, Mark is able to recognize his sister's voice and is relieved that she has found him. However, once Karin enters the room, Mark is furious as he still believes that she is a copy and was somehow able to mimic the real Karin on the phone. Though there was an initial success, Weber had not provided a scaffold for this experiment to lead to a treatment nor had he considered the potential damage to Mark's perception if the experiment failed. Weber admits that he didn't expect the experiment to work stating, "for a disconnection between the amygdala and the inferotemporal cortex to run roughshod over all higher cognition mocked any trust one put in consciousness" (Powers 162). While Weber admits that the issue is more complicated than a simple "short circuit," he still aims to further his research into the process of consciousness 
rather than focus on Mark's treatment (Powers 162). This experiment would be considered highly unethical as it caused both parties duress, and despite Mark's ability to recognize Karin's voice on the phone, it is not discussed again.

As with most neuronarratives, there is no clear section of neuroscience or treatment in this neuronovel as scientific research and terminology are interspersed throughout the text, so the readers learn alongside Karin and Mark. The reader typically depends on Karin for researching many articles trying to understand her brother's condition and asking Weber for explanations to understand the neuroscience behind Mark's condition. While Hayes and later Weber confirm Mark has Capgras Syndrome, Karin also suggests that he might be suffering from Fregoli Syndrome (the belief that someone is dressing up like other people) and Cotard Syndrome (the belief that you have died and are still existing). Though she produces research on both of these syndromes, neither of Mark's doctors spend much time on the diagnosis.

During his recovery from his suicide attempt, Weber returns and speaks with him. Mark has mixed feelings on his treatment claiming, "I'm going to start feeling better real soon, whether I want to or not. Yep, they are going to bring me back to myself. Mark Three" (Powers 414). Mark is clearly not responding to his initial treatment and still does not see a connection between his body and mind. There is also a clear distrust of the treatment as Mark indicates that he does not have a choice in his own recovery. Mark asks Weber, "My brain, all those split parts, trying to convince each other. Dozens of lost Scouts waving crappy flashlights in the woods at night. Where's me?" (Powers 415). Weber cannot answer him and can only offer that he will feel "more whole than you do now" (Powers 415). Despite great strides in research and countless writings on the subject, there is no clear answer on where the self or consciousness originates.

Weber's answer of wholeness relates to his debates about selfhood and consciousness throughout the book. In his fictional work The Three Pound Infinity, Weber claims that, "the self presents itself as whole, willful, embodied, continuous, and aware" (Powers 381). The brain is a very fast storyteller that takes information from many different areas of the brain to present a complete and continuous sense of reality. Weber argues that, "The job of consciousness is to make sure that all of the distributed modules of the brain seem integrated. That we always seem familiar to ourselves" (Powers 363). While Mark's memory is now intact and he is able to go about his day with limited problems, his sense of familiarity, both in regards to his family members and later himself, has been interrupted. As he describes himself as Mark Three, his sense of consciousness no longer feels familiar.

31 The fact that Mark believes that he is in someone else's dream or that he is dead suggests a separation from his own body and mind. This concern links back to Weber's earlier remark that, "the self is a mob, a drifting, improvised posse... no self without self-delusion" (Powers 358). Weber argues that we rewrite our perceptions and view those edits as the original, so delusion is inherent in consciousness. However, Julie Hawk claims that Weber's conclusions for understanding consciousness come through narrative and story-telling. In The Echo Maker, Weber cites his own fictitious work describing consciousness as re-telling stories without acknowledgment of changes, and Hawk states that this conclusion transforms as Weber comes to "view narrative as a strategy for healing or perhaps even self-actualization, despite the fact that the self, as it has been defined in liberal humanism at least, is itself a fiction" (Hawk 25). This argument supports Mark's questions of selfhood as he feels his self fracturing. While 
Webber assures Mark that he will feel "more whole," he internally acknowledges that he may be making a false promise (Powers 415).

Luc Herman and Bart Vervaeck argue that there is a contamination in the novel's multiple embedded narratives as multiple characters misread or misunderstand themselves or each other, as if Capgras Syndrome was contagious. Ultimately, the authors claim that both Mark and the reader are looking for coherence, which the book's structure prevents, yet the text does not feel incomplete, suggesting that it is the feeling of wholeness rather than actually being complete that is important. Mark is clearly fragmented himself through his suggestion that he will be Mark Three after his treatment, but Weber's consolation is that the treatment will make him feel more whole or restore the connection between his body and mind that has been shorn away, though he doesn't suggest that Mark will be exactly the same as Mark One or how he felt before the accident. Even with the restored connection between his brain and body, this experience will change Mark.

In Brain on Fire, Calahan also struggles with the continued separation of her selves. The last section of her neuromemoir focuses on Calahan's attempt to create a coherent self by trying to understand what is actually happening inside of her brain. There is another shift in the narrative in this section of the text as there is an increase of interviews with doctors and nurses, neurological tests, and results of research including her own brain cells on display. Cahalan writes, "Though I had been gradually losing more and more of myself over the past few weeks, the break between my consciousness and my physical body was finally fully complete. In essence, I was gone" (Cahalan 72). While there was an entry similar to this when she relied heavily on the perspective of her friends and family, she still had brief moments of clarity. However, this section marks a total reliance on others to explain the events before her diagnosis. As Cahalan notes, this process of losing herself was gradual, but this creates a disconnect between her physical self and her mental self. A clear example of this disconnect can be seen in Cahalan's review of videos of herself during her illness. Even though she continues to use the word "I" while reviewing these video tapes and meetings with medical professionals, there is a separation between the Cahalan who is in the recordings and the narrator. Though obviously separated by time and space, Cahalan regularly marks the differences physically with changing the form of text in transcripts and fragments of memories.

This separation of narrators is seen again when Cahalan is watching another video recording of herself lying down. She describes herself like a statue staring into nothing, but clearly terrified (175). Despite the fact that she does use the word "I" here, she makes a preface to explain that this is happening on the video, trying to distance herself from the woman on the screen. She points out that, "I have never seen myself so unhinged and unguarded before, and it frightens me" (175). There is a violation of privacy in this scene as Cahalan is completely vulnerable, unable to communicate. While she recognizes herself, "the thing that truly unsettles me is the realization that emotions I once felt so profoundly, so viscerally, have completely vanished... it's impossible for me to imagine what it must have been like to be her" (Cahalan 175). She further separates from this version of herself as she claims, "without this electronic evidence, I would have never imagined myself capable of such madness and misery" (Cahalan 175). This separation of selves makes this section of the narrative rely more heavily on authoritative sources, as Cahalan cannot always remember the exact events. 
However, she continues to keep her personal memories of the events alongside outside perspectives to keep the focus on her experience, both real and imagined.

Dr. Najjar, the doctor who would ultimately diagnose her, successfully incorporates more scientific research into the narrative. The readers see her "clock test, a classic test for visual neglect or visual indifference; the brain simply does not care about what's going on in the left side of its universe" (Cahalan 133). Cahalan incorporates images of her test, a clock with the numbers six through twelve running up the middle in a straight line instead of going around the circle, to show a physical example of her changed perception. In Cahalan's case, the right side of her brain had been affected by the anti-NDMA encephalitis, making the left side of her perspective altered. Showing this image not only educates the reader in what the test looks like, but again shows another private moment with Cahalan and her family as the narrative slowly begins to return back from the scientific perspective and into the mix of Cahalan and her social circle.

This shift is seen in Cahalan's inclusion of her own research into her illness narrative. As she moves forward with a brain biopsy and treatment, Cahalan includes more research such as brain slides from rat studies and researches the likelihood of recovery from this illness. To address this separation between the narrative and the scientific, Cahalan makes these studies personal by comparing the findings to herself. This again creates a separation between the ill and recovered versions of Cahalan as the readers understand that she does recover from this illness. However, the notes and discussions from family members and her medical professionals showcase the fear and uncertainty between the diagnosis and recovery as her symptoms worsened before they improved (Cahalan 144, 167).

Smith and Watson state that memory "is always implicated in materiality, whether it be the materiality of sound, stone, text, garment, integrated circuits and circuit boards or the materiality of our very bodies-the synapses and electrons of our brains and our nervous systems" (27). As Cahalan points out, this text is "a blend of memoir and reportage" (xi). She constructed the book through "hundreds of interviews with doctors, nurses, friends, and family; thousands of pages of medical records; [her] father's journal from this period; the hospital cameras during her stay; and notebooks upon notebooks of recollections, consultations, and impressions" (Cahalan xi). Reading this as a multilinear structure allows the third-person perspective of the family members and friends and the neuroscientific authority to be shown side by side with the patient's perspective.

\section{Return to Selfhood}

Even when treatment is successful, the definition of what is normal is forever altered by the experience of such drastic changes in consciousness. While the goal of Mark's treatment was to remove the delusions, just remembering is not enough for him to return to his life. In the last section of the novel, Mark's treatment is successful, and he realizes that Karin is his real sister. Even though this was the result Karin had wanted throughout the novel, instead of describing her brother as becoming whole again, she states, "the man who has been denying her is gone. In his place, a Mark she has never seen sits in a chair with striped pajamas" (Powers 443). Karin describes being close to Mark and helping raise him throughout the novel, so the fact that this is a version of 
Mark that Karin has never seen suggests that he has not returned to the old Mark, but has become someone else. Despite the fact that she immediately calls his transition back to knowing her "too seamless, too gradual in coming," it is clear that she does not equate the Mark in front of her to her image of her brother before the accident (Powers 443). While she describes the experience as watching "him turn back into Mark, old Mark, before her appalled eyes," her reaction betrays her actual feelings (Powers 444). In an odd mirroring of Mark's denial of her at the start of the novel, Karin struggles to connect her memory and feelings about Mark with the version of Mark before her. She cannot forget the year of Mark's refusal to accept her as his sister and she views Mark as "fully broken" when he realizes that he has lived with these delusions, believing them to be the truth (Powers 445). Mark has truly become Mark Three, as he no longer has the delusions of Mark Two, but his memory of the experience and the changes in his brain due to the accident have changed him.

Though Mark tries to tease Karin about her being an imposter, this joke acknowledges his fear of not knowing if his perception of reality is true. He states, "that is what scares me: if I could go so long, thinking...? Then how can we be sure, even now...?" (Powers 447). Mark's realization that his version of reality was deeply flawed would obviously be disconcerting. Weber relates this situation in an interview, claiming that, "consciousness works by telling a story, one that is whole, continuous, and stable. When that story breaks, consciousness rewrites it. Each revised draft claims to be the original. And so, when disease or accident interrupts us, we're often the last to know" (Powers 185). The brain is so good at seamlessly connecting millions of pieces of information to create our sense of reality and we have years of having that perception guide us, it is difficult to acknowledge that the brain is the problem, rather than the world.

Cahalan also struggles with trusting her perception, even as she begins to recover. By the end of the neuromemoir, Cahalan describes herself more cohesively. As she improves at the hospital she describes her growing awareness as "evidence of my budding self" and though she describes the entries as "childlike and prosaic," she recognizes aspects of herself (197). Instead of separating herself into multiple versions she writes, "this new Susannah is a lot like the old Susannah. There are changes, but it's more like a step to the left than an overhaul of my being" (Cahalan 239). This is a very different description compared to her previous more animalistic comparisons between her "selves." She acknowledges that she is "different," but while she still has legitimate concerns regarding a risk of relapse, she focuses more on the changes of the people around her. Her boyfriend now has to relinquish the role of caretaker and become a partner again. While her parents bonded over the experience of taking care of her, they remained divorced and grew apart again once her health improved. Her friends and colleagues claim that "Susannah is back" and she was able to return to work, but the memory of these events remained (Cahalan 238). While the majority of the fractures created in the narrative come back together, not unlike illnesses, they have left their marks even after healing.

\section{Conclusion}

Memory is clearly linked to the concept of selfhood as Mark and Cahalan focus on piecing together their previous experiences to better regain their sense of selves. The 
understanding of who we are and how we came to be is built up through a series of experiences and feelings. In The Man Who Mistook His Wife for a Hat, Oliver Sacks states that, "each of us is a singular narrative, which is constructed, continually, unconsciously, by, through, and in us- through our perceptions, our feelings, our thoughts, our actions; and not least, our discourse, our spoken narratives" (110-111). In both the neuronovel The Echo Maker and the neuromemoir Brain on Fire, the goal is to piece together self-perception, memories and artifacts from others, and scientific explanations to regain an understanding of consciousness after both of the main characters experience physical changes in their brains. Sacks argues that "to be ourselves we must have ourselves-possess, if need be re-possess, our life-stories. We must 'recollect' ourselves, recollect the inner drama, the narrative, of ourselves" (Sacks 110-111). Neuronarratives can provide opportunities to explore what it means to re-possess ourselves and to better understand how consciousness is formed.

While neuroscience and narrative may seem disparate, there has been a growing interest in the combination of literature and the sciences. Instead of drawing a clear division in methodology regarding selfhood and consciousness, by combining the arts and sciences together, neuronarratives provide an opportunity to examine the divisions of our perceptions that we regularly combine to form our sense of consciousness. It is important to note that there can be problems with appropriation of scientific terms and misunderstanding or over-simplifying in the process of incorporating them into the narrative. Philosopher Patricia Churchland terms these oversimplified concepts as "neurojunk" (19). Brain science is rarely straightforward and rapidly changes as new technologies and studies continue to complicate what we think we understand about the brain. There are also concerns about continuing stigmas against mental health conditions, especially if the neuronarrative relies on oversimplified neurojunk for the basis of its narrative. These are the growing pains that neuronarratives must continue to struggle through, but they remain a genre worth pursuing as opportunities to better understand ourselves and how we perceive the world around us.

As we continue to strive to understand the human experience, there are great benefits for combining the humanities and the sciences through narrative. Ricardo MiguelAlfonso argues that "studying narrative becomes essential for our understanding of the mind itself... in this sense, there is a close connection between narrative and expression of mind, the former being the natural vehicle of the latter both in the real world and in the artistic, fictional compositions" (1). There is a growing interest in narrative medicine in the sciences. According to medical doctor George Zaharias, the medical community has acknowledged the power of story-telling through the combination of narrative with science to provide a fuller picture of our thought process and sense of self (179). While the result of the connections of millions of neurons is a smooth and linear perception of the self and the world around us, neuronarratives can complicate this process by revealing the divisions and occasional contradictions that occur in the combination. Through the blending of narrative and science, we can better articulate the human experience. Continued experimentation with form and discipline is paramount for the growth of expression and neuronarratives are a growing genre to expand discussion of memory and consciousness 


\section{BIBLIOGRAPHY}

Barry, Helen et al. "Anti-N-methyl-d-aspartate receptor encephalitis: review of clinical presentation, diagnosis and treatment." BJPsych Bulletin, vol. 39, no. 1, 2015, pp. 19-23.

Cahalan, Susannah. Brain on Fire: My Month of Madness. Simon and Schuster, 2012.

Churchland, Patricia. Touching a Nerve: Our Brains, Our Selves. W.W. Norton, 2013.

Hawk, Julie. “The Observer's Tale: Dr. Weber's Narrative (and Metanarrative) Trajectory in Richard Powers's The Echo Maker." Critique: Studies in Contemporary Fiction, vol. 54, no. 1, 2013, pp. 18-27.

Herman, Luc, and Bart Vervaeck. "Capturing Capgras: The Echo Maker by Richard Powers." Style: A Quarterly Journal of Aesthetics, Poetics, Stylistics, and Literary Criticism, vol. 43, no. 3, 2009, pp. 407-428.

Hirstein, William, and V. S. Ramachandran. "Capgras syndrome: a novel probe for understanding the neural representation of the identity and familiarity of persons." Proceedings. Biological Sciences, vol. 264, no. 1380, 1997, pp. 437-444.

Johnson, Gary. "Consciousness as Content: Neuronarratives and the Redemption of Fiction." Mosaic, vol. 41, no. 1, March 2008, pp. 169-184.

Knirsch, Christian. "Richard Powers's The Echo Maker: Reassessing the Neuronovel in American Literature.” Amerikastudien, vol. 59, no 1, March 2014, pp. 47-62.

Levine, Joseph. “Materialism and Qualia: The Explanatory Gap.” Pacific Philosophical Quarterly, vol. 64, October 1983, pp. 354-361.

Miguel-Alfonso, Ricardo. The Fictional Minds of Modernism: Narrative Cognition from Henry James to Christopher Isherwood. Bloomsbury Academic, 2020.

Ortega, Francisco, and Fernando Vidal. "Brains in Literature/Literature in the Brain." Poetics Today, vol. 34, no. 3, Fall 2013, pp. 327-359.

Powers, Richard. The Echo Maker. Farrar, Straus, and Giroux, 2006.

Sacks, Oliver. The Man Who Mistook His Wife for a Hat and Other Clinical Tales. Simon and Schuster, 1970.

Smith, Sidonie, and Watson, Julia. Reading Autobiography: A Guide for Interpreting Life Narratives. U of Minnesota P, 2010.

Starck, Lindsay. "The Matter of Literary Memory: Virginia Woolf's Mrs. Dalloway and Ian McEwan's Saturday." Adaptation, vol. 9, no. 3, 2016, pp. 328-344.

Tougaw, Jason. The Elusive Brain: Literary Experiments in the Age of Neuroscience. U of Yale P, 2018.

Torales, Julio, et al. "Olanzapine in the Treatment of Capgras Syndrome: A Case Report."

International Journal of Culture and Mental Health, vol. 7, no. 2, 2014, pp. 224-228.

Yalin, şermin, et al. "The Coexistence of Capgras, Fregoli and Cotard's Syndromes in an Adolescent Case." Archives of Neuropsychiatry / Noropsikiatri Arsivi, vol. 45, no. 4, December 2008, pp. 149-151.

Zaharias, George. "What is Narrative-Based Medicine?" Can Fam Physician, vol. 64, no. 3, March 2018, pp. 176-180. 


\section{NOTES}

1. Anti-NMDA receptor encephalitis is primarily found in women and symptoms such as hallucinations, motor disfunctions, delusions, and seizures are common (Barry et al.). With proper treatment, the majority of patients recover, though some remain severely impacted or may die due to the condition (Barry et al.).

\section{ABSTRACTS}

This paper will focus on two works: the neuronovel The Echo Maker (2006) by Richard Powers, a fictional account of Mark Schluter who suffers from Capgras Syndrome, that is, a rare neurological condition that results in the patient's belief that their loved ones have been replaced with exact copies; and the neuromemoir Brain on Fire: My Month of Madness (2012) by Susannah Cahalan, which describes Cahalan's experiences as she is diagnosed with anti-NMDA receptor encephalitis, a rare auto-immune disease. Both works have protagonists that suffer from a serious brain illness and must rely on their own perceptions, those of family and friends, and neuroscientific research in order to heal and create a more cohesive sense of self again. I argue that The Echo Maker and Brain on Fire complicate the perception of selfhood as the main character in each text can no longer trust their own perceptions and must instead weave together their fragmented personal experience, background from their social groups, and scientific explanations of their conditions to regain a sense of self. The narratives of The Echo Maker and Brain on Fire combine these different perspectives in an effort to regain a sense of selfhood that brain damage has fractured. While the result of the connections of millions of neurons is a smooth and linear perception of the self and the world around us, neuronarratives can complicate this process by revealing the divisions and occasional contradictions that occur in the combination.

\section{INDEX}

Keywords: neuronovel, neuromemoir, consciousness, selfhood, The Echo Maker, Brain on Fire, brain trauma, brain disease

\section{AUTHOR}

\section{BONNIE CROSS}

Bonnie Cross is a Tenure Track Professor of English at Valencia College and a PhD student in Texts and Technology at the University of Central Florida. Her research interests currently focus on hypertext, comic studies, and the intersection between neuroscience and literature. Her dissertation will focus on neurocomics and digital narratives. 